NBER WORKING PAPER SERIES

GAINS FROM FDI INFLOWS WITH INCOMPLETE INFORMATION

Assaf Razin

Efraim Sadka

Working Paper 9008

http://www.nber.org/papers/w9008

NATIONAL BUREAU OF ECONOMIC RESEARCH

1050 Massachusetts Avenue

Cambridge, MA 02138

June 2002

The views expressed herein are those of the authors and not necessarily those of the National Bureau of Economic Research.

(C) 2002 by Assaf Razin and Efraim Sadka. All rights reserved. Short sections of text, not to exceed two paragraphs, may be quoted without explicit permission provided that full credit, including $(\mathcal{C}$ notice, is given to the source. 
Gains from FDI Inflows with Incomplete Information

Assaf Razin and Efraim Sadka

NBER Working Paper No. 9008

June 2002

JEL No. F2, F3

\begin{abstract}
The paper develops an international macroeconomic model of FDI flows with a unique feature: a hands-on management ability to react in real time to changing economic environments. Anticipating this advantage, foreign direct investors can outbid other investors in a certain industry in which they specialize in the source country. The model can explain both two-way FDI flows among developed countries and one-way FDI flows from developed to developing country. The unique gains from FDI to the host country stem from the increased eciency of domestic investment.
\end{abstract}

Assaf Razin

Department of Economics

Tel Aviv University

Tel Aviv, 69978

Israel

and NBER

razin@post.tau.ac.il
Efraim Sadka

Tel Aviv University

Tel Aviv, 69978

Israel 


\title{
Gains from FDI Inflows with Incomplete Information*
}

\author{
Assaf Razin ${ }^{\dagger}$ and Efraim Sadka ${ }^{\ddagger}$
}

March 2002

\begin{abstract}
A bstract
The paper develops an international macroeconomic model of FDI flows with a unique feature: a hands-on management ability to react in real time to changing economic environments. Anticipating this advantage, foreign direct investors can outbid other investors in a certain industry in which they specialize in the source country. The model can explain both two-way FDI flows among developed countries and one-way FDI flows from developed to developing country. The unique gains from FDI to the host country stem from the increased efficiency of domestic investment.
\end{abstract}

JEL.Nos. F2. F3.

Keywords: FDI vs. Portfolio. Free-Rider Problem. Control. Gains-from-Capital Inflows. Asymmetric Information.

\section{Introduction}

In perfect capital markets (with full information) all forms of capital flows (FDI, debt and portfolio equity) are indistinguishable. In the presence of incomplete information, these flows are different from one another. ${ }^{1}$ For instance, firm mnagement with portfolio investment might be plagued by a "freerider" problem. As noted succintly by Oliver Hart (2000), "if the shareholder does something to improve

\footnotetext{
${ }^{*}$ The authors are grateful to Philip Lane and Morten Raven for helpful comments and suggestions on an earlier draft and to the European Commission for financial support for the RTN project, "Analysis of International Capital Markets: Understanding Europe's Role in the Global Economy."

${ }^{\dagger}$ Mario Henrique Simonsen Professor of Public Economics, Tel-Aviv University and Friedman Professor of International Economics, Cornell University, razin@post.tau.ac.il; fax: 972-3-6409908.

${ }^{\ddagger}$ Henry Kaufman Professor of International Capital Markets, Tel-Aviv University, sadka@post.tau.ac.il; fax: 972-36409908 .

${ }^{1}$ Other models that attempt to distinguish among capital flows [e.g., Gordon and Bovenberg (1996), Razin, Sadka and Yuen $(1998,1999)$ ] assumed segmented markets both across FDI, debt and portfolio equity and across countries. In these models there is an information asymmetry between domestic and foreign investors, which leads to a home bias in portfolio equity investment. An interesting empirical study of these asymmetry and bias is provided in Portes and Rey (1999).
} 
the quality of management, then the benefits will be enjoyed by all shareholders. Unless the shareholder is altruistic, she will ignore this beneficial impact on other shareholders and so will under-invest in the activity of monitoring or improving management."

We view FDI as having a unique characteristic with respect to the quality of management. Foreign direct investors, by definition, acquire some significant control over the firm they invest in. They can then apply hands-on management (micro-management) standards that enable them to react in real time to changing economic environments. They can obtain the full benefits of their actions of monitoring the firm for themselves because they gain control over the firm, and thereby mitigating the free-rider problem. This feature may stem from a specialization by the foreign direct investors in a certain niche. ${ }^{2}$ This could explain both two-way flows of FDI among developed economies, and one-way flows from developed to developing economies.

In this paper we explore the implications of this unique feature of FDI for the efficiency of domestic investment and the gains from FDI inflows. The organization of the paper is as follows. Section 2 develops a model of FDI flows with incomplete information and micro-management of FDI-controlled firms. In Section 3 we describe the equilibrium in the absence of FDI. Section 4 discusses the gains from FDI trade. Section 5 concludes.

\section{Free Flow of FDI}

Suppose there is a very large number $(N)$ of ex-ante identical domestic firms. Each firm employs capital input $(K)$ in the first period, in order to produce a single composite good in the second period. We assume that capital depreciates at the rate $\delta(<1)$. Output in the second period is equal to $F(K)(1+\varepsilon)$, where $F(\cdot)$ is a production function exhibiting diminishing marginal productivity of capital and $\varepsilon$ is a random productivity factor. The latter has zero mean and is independent across all firms. Naturally, $\varepsilon$ is bounded below by -1 , so that output is always non-negative; and for notation ease we also assume that $\varepsilon$ is bounded from above by 1 . Suppose that $\varepsilon$ is purely idiosyncratic, so that there is no aggregate uncertainty. Consumer-investors are well diversified and will thus behave in a risk-neutral way. We denote by $G(\cdot)$ the cumulative distribution function of $\varepsilon$ and by $g(\cdot)=G^{\prime}(\cdot)$ the corresponding density function.

At the starting point of the decision process of agents in the first period, the random productivity factor $(\varepsilon)$ is revealed to no-one. Each firm is endowed with an initial stock of capital $K_{0}$. In order to

\footnotetext{
${ }^{2}$ See Gopinath (2001) for an interesting application of a search model for a study of FDI flows to developing economies.
} 
invest and augment this stock of capital the firm must incur first a fixed setup cost of $C$. Because the firms are all ex-ante (that is, in the first period, when investments are made) identical, they all choose the same investment, $K_{1}^{\mathrm{F}}-(1-\delta) K_{0}$ to augment their capital stock to $K_{1}^{\mathrm{F}}$. The investment decision is based on the average value of $\varepsilon$ (which is zero) according to the first-order marginal productivity condition:

$$
F^{\prime}\left[K_{1}^{\mathrm{F}}\right)=\delta+r^{\mathrm{F}}
$$

where $r^{\mathrm{F}}$ is the exogenously given world rate of interest. Because the firm has also the alternative of not investing at all and avoiding the setup cost, then it will indeed invest and augment its capital stock to $K_{1}^{\mathrm{F}}$, if and only if:

$$
\begin{aligned}
& \frac{F\left(K_{1}^{\mathrm{F}}\right)+(1-\delta) K_{1}^{\mathrm{F}}}{1+r^{\mathrm{F}}}-\left[K_{1}^{\mathrm{F}}-(1-\delta) K_{0}-C\right] \\
= & \frac{\left\{F\left[(1-\delta) K_{0}\right]+(1-\delta)^{2} K_{0}\right\}}{1+r^{\mathrm{F}}} .
\end{aligned}
$$

The left-hand-side of (2) is equal to cash flow (in present value) with new investment, whereas the right-hand-side is equal to the corresponding cash flow with no new investment. We assume that this condition indeed holds so that all firms would have indeed invested $K_{1}^{\mathrm{F}}-(1-\delta) K_{0}$, if this were all the information available at this stage.

Now, suppose that at this stage (before $\varepsilon$ is revealed) foreign direct investors step in and bring with them their superior micro-management skills. Specifically, we assume that an FDI investor, once acquiring and managing a firm, can better monitor the productivity of the firm (before investment in physical capital is carried out) than her domestic counterpart. To simplify things, assume that the FDI investor can actually elicit the true $\varepsilon$ of the firm, after she acquires control of the firm, but before she has to carry out the investment plan. She can thus fine tune the level of the capital stock to the true $\varepsilon$. Put differently, the FDI investor will carry out an $\varepsilon$-dependent schedule, $K_{1}^{\mathrm{F}}(\varepsilon)$ which is determined as follows. First, if the firm decides to make new investment, it will change the capital stock to $\hat{K}_{1}^{\mathrm{F}}(\varepsilon)$ defined implicitly by:

$$
F^{\prime}\left(\hat{K}_{1}^{\mathrm{F}}(\varepsilon)\right)=r^{\mathrm{F}}+\delta
$$

Naturally, the firm will actually carry out this investment plan only if it is preferable to not investing 
at all. Therefore, there exists a cutoff level of the productivity factor, denoted by $\varepsilon_{0}^{F}$, such that the firm will indeed augment its capital stock to $\hat{K}_{1}^{\mathrm{F}}(\varepsilon)$, if its productivity factor is above this threshold; otherwise the firm will make no new investment and operate do with its initial stock of capital [namely, $\left.(1-\delta) K_{0}\right]$. That is:

$$
K_{1}^{\mathrm{F}}(\varepsilon)=\left\{\begin{array}{c}
(1-\delta) K_{0} \text { if } \varepsilon 5 \varepsilon_{0}^{\mathrm{F}} \\
\hat{K}_{1}^{\mathrm{F}}(\varepsilon) \text { if } \varepsilon=\varepsilon_{0}^{\mathrm{F}}
\end{array}\right.
$$

The cutoff level $\varepsilon_{0}^{\mathrm{F}}$ is defined implicitly by an indifference condition between investing and not investing:

$$
\begin{aligned}
& \frac{F\left[\hat{K}_{1}^{\mathrm{F}}\left(\varepsilon_{0}^{\mathrm{F}}\right)\right]\left(1+\varepsilon_{0}^{\mathrm{F}}\right)+(1-\delta) \hat{K}_{1}^{\mathrm{F}}\left(\varepsilon_{0}^{\mathrm{F}}\right)}{1+r^{\mathrm{F}}}-\left[\hat{K}_{1}^{\mathrm{F}}\left(\varepsilon_{0}^{\mathrm{F}}\right)-(1-\delta) K_{0}-C\right] \\
= & \frac{F\left[(1-\delta) K_{0}\right]+(1-\delta)^{2} K_{0}}{1+r^{\mathrm{F}}} .
\end{aligned}
$$

Anticipating this fine-tuned investment schedule, the value to a potential FDI investor of a domestic firm at the time of purchase (namely, before $\varepsilon$ is revealed), denoted by $V$, is given by:

$$
V=\int_{-1}^{1}\left\{\frac{F\left[K_{1}^{\mathrm{F}}(\varepsilon)\right](1+\varepsilon)+(1-\delta) K_{1}^{\mathrm{F}}(\varepsilon)}{1+r^{\mathrm{F}}}-\left[K_{1}^{\mathrm{F}}(\varepsilon)-(1-\delta) K_{0}-\alpha(\varepsilon) C\right]\right\} d G(\varepsilon)
$$

where

$$
\alpha(\varepsilon)=\left\{\begin{array}{l}
0 \text { if } \varepsilon<\varepsilon_{0}^{F} \\
1 \text { if } \varepsilon \geq \varepsilon_{0}^{F}
\end{array}\right.
$$

The initial domestic owner, if she does not sell the firm, will carry out the same ( $\varepsilon$-independent) investment [namely, $K_{1}^{\mathrm{F}}-(1-\delta) K_{0}$ ] for all the (ex-ante identical) firms. Therefore the reservation price of the initial domestic owner, denoted by $R^{\mathrm{F}}$, is the expected value of its discounted cash flow which is given by:

$$
R^{\mathrm{F}}=\frac{F\left(K_{1}^{\mathrm{F}}\right)+(1-\delta) K_{1}^{\mathrm{F}}}{1+r^{\mathrm{F}}}-\left[K_{1}^{\mathrm{F}}-(1-\delta) K_{0}-C\right]
$$

Note that the value of a firm to an FDI investor (namely, $V$ ), which is generated by a fine-tuned investment schedule, $K_{1}^{\mathrm{F}}(\varepsilon)$, will be higher than the reservation price of the domestic owner (namely, 
$R^{\mathrm{F}}$ ). Therefore, FDI investors will outbid domestic investors for all the firms in this industry. Because we assume that there is an infinitely elastic supply of foreign direct investors faced by our small open economy, then competition among these investors will drive the price up to $V$, thereby generating a pure rent of $V-R^{\mathrm{F}}$ to the initial owners of each of the fixed number of the domestic firms.

To complete the description of the equilibrium, denote the aggregate output available in the first period for consumption and investment by $F\left(K_{0}\right)$. Then the consolidated (present-value) resource constraint is given by:

$$
C_{1}^{\mathrm{F}}+\frac{C_{2}^{\mathrm{F}}}{1+r^{\mathrm{F}}}=F\left(K_{0}\right)+V
$$

where $C_{\mathrm{i}}^{\mathrm{F}}$ is consumption in period $i=1$, 2. (For notational ease we ignore all other industries in this economy.) We also have the standard intertemporal-consumption allocation rule:

$$
u_{1}\left(C_{1}^{\mathrm{F}}, C_{2}^{\mathrm{F}}\right) / u_{2}\left(C_{1}^{\mathrm{F}}, C_{2}^{\mathrm{F}}\right)=1+r^{\mathrm{F}},
$$

where $u(\cdot)$ is the representative utility function and where $u_{\mathrm{i}}(\cdot), i=1,2$, stands for a partial derivative.

\section{Absence of FDI Flows}

In order to assess the gains from FDI (to be discussed in the next section), we must consider an equilibrium where FDI is absent. To save on words, we refer to this equilibrium as an autarky. Denoting the equilibrium interest rate by $R^{\mathrm{A}}$, we implicitly define the equilibrium stock of capital, $K_{1}^{\mathrm{A}}$, by:

$$
F^{\prime}\left(K_{1}^{\mathrm{A}}\right)=r^{\mathrm{A}}+\delta
$$

We assume that:

$$
\frac{F\left(K_{1}^{\mathrm{A}}\right)+(1-\delta) K_{1}^{\mathrm{A}}}{1+r^{\mathrm{A}}}-\left[K_{1}^{\mathrm{A}}+(1-\delta) K_{1}^{\mathrm{A}}-C\right] \geq \frac{F\left[(1-\delta) K_{0}\right]+(1-\delta)^{2} K_{0}}{1+r^{\mathrm{A}}},
$$

so that it is indeed worthwhile to augment the capital stock of all the ex-ante identical firms to $K_{1}^{\mathrm{A}}$.

The period-by-period resource constraints, that must hold at autarky, are given by:

$$
C_{1}^{\mathrm{A}}+\left[K_{1}^{\mathrm{A}}(1-\delta) K_{0}-C\right]=F\left(K_{0}\right)
$$

and 


$$
C_{2}^{\mathrm{A}}=F\left(K_{1}^{\mathrm{A}}\right)+(1-\delta) K_{1}^{\mathrm{A}}
$$

and the intertemporal allocation condition is:

$$
u_{1}\left(C_{1}^{\mathrm{A}}, C_{2}^{\mathrm{A}}\right) / u_{2}\left(C_{1}^{\mathrm{A}}, C_{2}^{\mathrm{A}}\right)=1+r^{\mathrm{A}}
$$

where $C_{\mathrm{i}}^{\mathrm{A}}$ is the consumption in period $i=1,2$ at autarky.

\section{Gains from FDI}

The ex-ante (expected) gains from FDI are in line with the traditional trade proposition: They accrue entirely to the domestic, small economy. (Recall that the FDI investors pay a price $V$ for all domestic firms which captures all the benefits from the superior FDI management skills, thus leaving the FDI investors with a return just equalling the world rate of interest.) We can classify these gains into two categories. First, there are the conventional gains that stem from opening up the economy to the flow of capital, thereby allowing a more efficient intertemporal allocation of consumption (usually via consumption smoothing) and investment. Second, there are the intrinsic gains associated with the superior micro-management by FDI investors. These gains stem from a fine-tuned capital stock, $K_{1}^{\mathrm{F}}(\cdot)$ brought about by FDI investors, as opposed to a uniform (over all firms) capital stock, $K_{1}^{\mathrm{F}}$, which domestic investors would have chosen in the absence of FDI. This advantage gives rise to a value of $V$ for a domestic firm to an FDI investor, which is higher than the value of the firm (namely, the reservation price $R^{\mathrm{F}}$ ) in the absence of FDI. But this gap (namely, $V-R^{\mathrm{F}}$ ) is entirely captured by the domestic economy, because of perfect competition among FDI investors for the fixed number of the domestic firms. These fine-tuning gains are represented by:

$$
V-R^{\mathrm{F}}=-\int_{-1}^{1} \frac{\left\{F\left[K_{1}^{\mathrm{F}}(\varepsilon)\right]-F\left(K_{1}^{\mathrm{F}}\right)\right\}(1+\varepsilon)-\left(r^{\mathrm{F}}+\delta\right)\left[K_{1}^{\mathrm{F}}(\varepsilon)-K_{1}^{\mathrm{F}}\right]}{1+r^{\mathrm{F}}} d G(\varepsilon)+G\left(\varepsilon_{0}^{\mathrm{F}}\right) C
$$

These fine-tuning gains consist of: (i) the expected present value of the additional benefits from having a capital stock of $K_{1}^{\mathrm{F}}(\varepsilon)$ instead of $K_{1}^{\mathrm{F}}$,when the productivity factor is $\varepsilon^{;}{ }^{3}$ and (ii) the saving of the "sunk" cost $C$ in all the low-productivity firms [whose number is $G\left(\varepsilon_{0}^{\mathrm{F}}\right)$ ].

\footnotetext{
${ }^{3}$ The additional benefits consist of the extra output, $\left\{F\left[K_{1}^{\mathrm{F}}(\varepsilon)\right]-F\left(K_{1}^{\mathrm{F}}\right)\right\}(1+\varepsilon)$, minus the user cost of the additional capital, $\left(r^{\mathrm{F}}+\delta\right)\left[K_{1}^{\mathrm{F}}(\varepsilon)-K_{1}^{\mathrm{F}}\right]$.
} 


\section{Conclusion}

The model presented here is extended in Razin and Sadka (2002) to include a screening (or search) technology that at some fixed cost per firm can elicit the true value of the productivity factor of the firm, $\varepsilon$. A potential buyer can apply the technology after she acquires and gains control of the firm. We assume that foreign direct investors have a cutting-edge advantage over domestic investors in extracting information about the true value of the firm. If they acquire a domestic firm, they can apply their superior micro-management skills in order to elicit the true value of the productivity factor. This advantage stems from their special experience and know-how in this particular industry. In this case FDI investors outbid other investors for the top productivity firms.

Empirically, developing countries with weak financial institutions, and low corporate governance and accounting standards attract a higher share of their capital inflows in the form of FDI [see, for instance, Loungani and Razin (2001)]. This finding is consistent with the main implication of our model. In a similar vein, our model can explain two-way flows of FDI among developed countries, as each country can specialize and acquire better management standards in different niches.

\section{References}

[1] Gopinath, Gita (2001), "Lending Booms, Sharp Reversals and the Real Exchange Dynamics", mimeo, University of Chicago, GSB.

[2] Gordon, Roger H. and A. Lars Bovenberg (1996), "Why is Capital so Immobile Internationally? Possible Explanations and Implications for Capital Income Taxation", American Economic Review $86,1057-75$.

[3] Hart, Oliver (2000), "Financial Contracting," Nancy L. Schwartz Lecture, Kellogg Graduate School of Management, Northwestern University.

[4] Portes, Richard and Helene Rey (1999), "The Determinants of Cross-Border Equity Flow: The Geography of Information," NBER Working Paper No. 7336.

[5] Loungangi, Prakash and Assaf Razin (2001), "Foreign Direct Investment: A Critical View," Financial and Development, Volume 38, Number 2, June, pp. 6-10. 
[6] Razin, Assaf and Efraim Sadka (2002), "FDI Flows, Portfolio Flows and Domestic Investment: The Role of Information," paper presented at the Sapir Center Conference "FDI: Theory and Evidence," Tel-Aviv University, May 15.

[7] Razin, Assaf, Efraim Sadka, and Chi-Wa Yuen (1998), "A Pecking Order of Capital Inflows and International Tax Principles", J ournal of International E conomics 44, 45-68.

[8] _ _ _ _ _ _ _ (1999), "Implications of the Home Bias: A Pecking Order of Capital Flows and Corrective Taxation", in: Assaf Razin and Efraim Sadka (editors), Globalization: Public Economics Perspectives, Cambridge University Press. 